Original article

https://www.journal-imab-bg.org

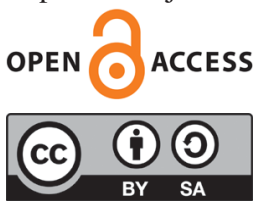

\title{
OCCUPATIONAL-RELATED INJURIES OF THE PERIPHERAL NERVOUS SYSTEM IN MECHANI- CAL ENGINEERING WORKERS IN NORTHERN BULGARIA
}

\author{
Irena Y. Stoilova ${ }^{1}$, Radostina P. Madjarova ${ }^{2}$, Vanya A. Birdanova ${ }^{1}$ \\ 1) Department Hygiene, medical ecology, occupational diseases and disaster \\ medicine, Medical University - Pleven, Bulgaria. \\ 2) Department Physical medicine and rehabilitation, occupational therapy and \\ sports, Medical University - Pleven, Bulgaria.
}

\section{SUMMARY}

Mechanical engineering is traditionally well developed in Northern Bulgaria. With the development of production and technical progress, some health problems for workers appear. The aim of this study was to examine the damage of the peripheral nervous system in workers in mechanical engineering and to propose measures for the prevention of accidents and occupational diseases. Subjects of the study are 65 persons employed in mechanical engineering. Conclusions are made and recommendations given for improvement of the work conditions and organization of the work.

Keywords: mechanical engineering, peripheral nervous system, harmful industrial factors,

\section{BACKGROUND}

Mechanical engineering is an important branch of the Bulgarian economy.

It includes a large number of sub-sectors - heavy engineering, vehicle production, automotive, aircraft, metal cutting machines, agricultural machinery and more. The production processes that take place in machinebuilding enterprises are diverse and complex [1]. Nevertheless, many homogeneous production processes are used in different sub-sectors. The work of workers in mechanical engineering is characterized by light, and medium physical exertion often requires forced working posture, increased attention and precision in performing production operations $[2,3]$.

The production stages in mechanical engineering include: obtaining parts with a certain shape by casting, forging and pressing; the processing of the obtained details through the use of various metal-cutting machines; installation of the processed details and receipt of the machines and equipment; painting of the manufactured machines and metal coating of their parts [4].
The occupational risk of investigated persons reduces systemic overvoltage of the peripheral nervous system under labor conditions [5].

\section{TARGET:}

The aim of the study is to examine the damage to the peripheral nervous system in workers in mechanical engineering and to propose measures for the prevention of accidents at work and occupational diseases.

\section{MATERIALS AND METHODS:}

The subject of the study is 65 cases of damage of the peripheral nervous system in patients hospitalized in the Department of Occupational diseases, University Hospital - Pleven in the period 2018-2020. The subjects are workers of enterprises in the districts of Pleven, Lovech, Vratsa, Gabrovo and Veliko Tarnovo. All the persons investigated were given information regarding the aim and the nature of the investigation and signed an informed consent form for undergoing the investigation.

Clinical, laboratory, functional, imaging and statistical methods have been used [6]. The clinical methods of diagnosis are professional anamnesis and production characteristics, clinical anamnesis, general status, neurological status, palpation, percussion, auscultation. The laboratory methods are hematological tests - CBC (complete blood count), the morphology of erythrocytes; biochemical tests - fat metabolism, enzymes, electrolytes, liver samples, etc.; immunological and serological tests [7]. The statistic processing of the primary data was done by software packages Microsoft Office Excel 2010 and SPSS ver. 13.

\section{RESULTS:}

The total number of respondents is 65 . From the inquired person, $83 \%$ were men, and $17 \%$ were women (Figure 1). 
Fig. 1. Distribution of persons by gender

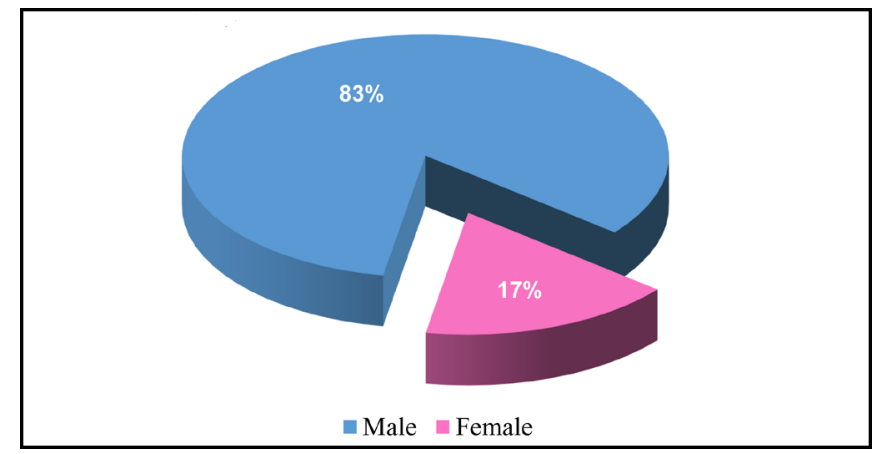

The respondents are aged from 21 to 62 years, and the average age is $44,00(n=65) \pm 2,88$ years. More than half of the inquired persons are between 41 and 60 years, followed by the ones between 31 and 40 years $-21,54 \%$, and $16,92 \%$ of them are between 21 and 30 years. The distribution of the surveyed persons by age is shown in Figure 2.

Fig. 2. Distribution of persons by age

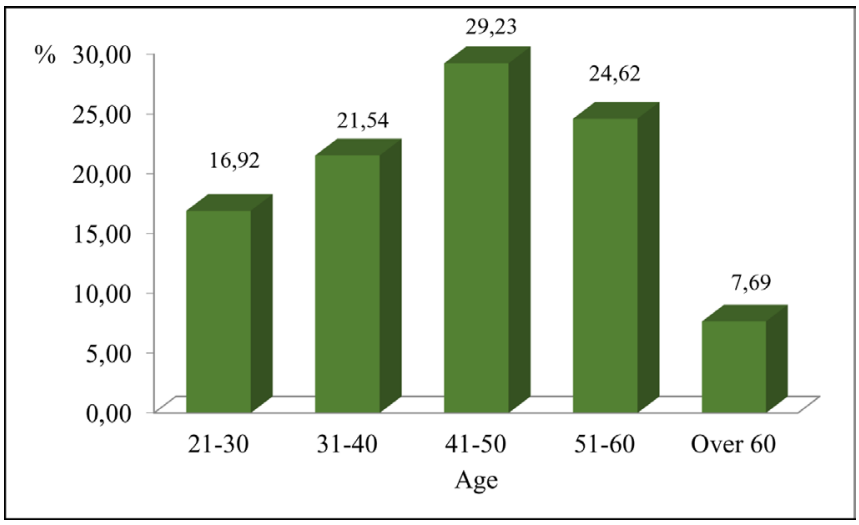

The surveyed workers are divided into the following professional groups:

Grinder $-17 \%$ of persons

Operator of metal cutting machines $-28 \%$ of persons

Turner and miller $-32 \%$ of persons

Welder $-23 \%$ of persons

The distribution of persons by occupation is shown in Figure 3.

Fig. 3. Distribution of persons by occupation

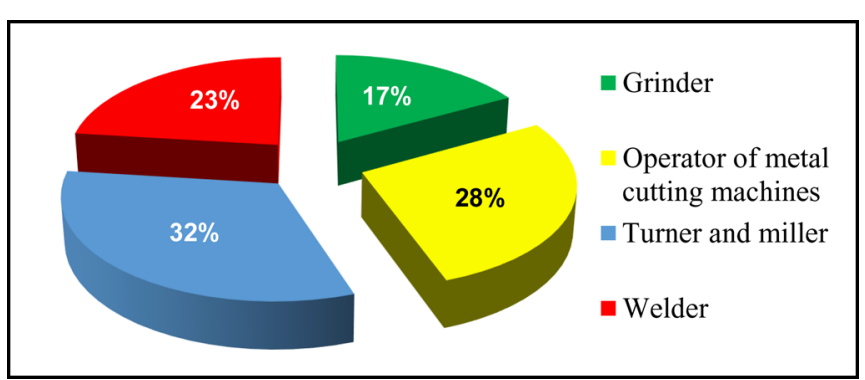

The subjects reported differences in working posture when performing work operations. Only operators of metal cutting machines are in a forced sitting posture.

Forced sitting posture $-28 \%$ of persons

Forced standing posture $-54 \%$ of persons

Free posture $-18 \%$ of persons

The distribution of subjects by working posture is shown in Figure 4.

Fig. 4. Distribution of persons by working posture

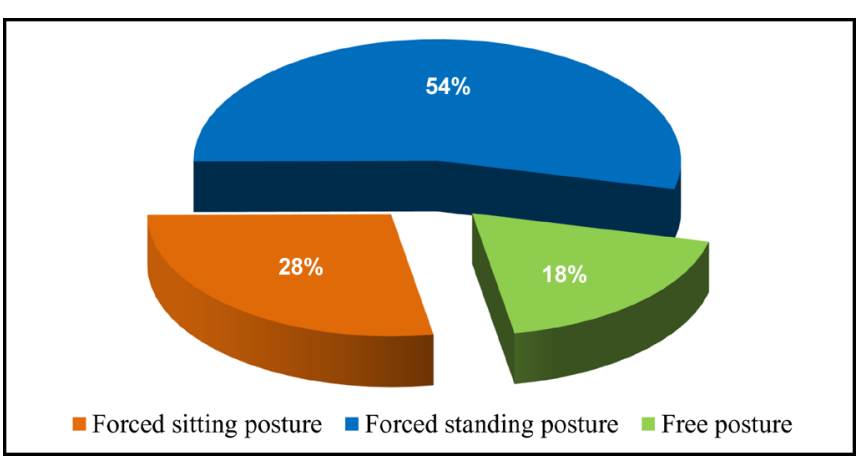

According to the place of residence, the participants are distributed as follows:

- Urban residents $-62 \%$ of persons

- Rural residents $-38 \%$ of persons

The distribution of participants according to the place of residence is shown in Figure 5.

Fig. 5. Distribution of participants according to the place of residence

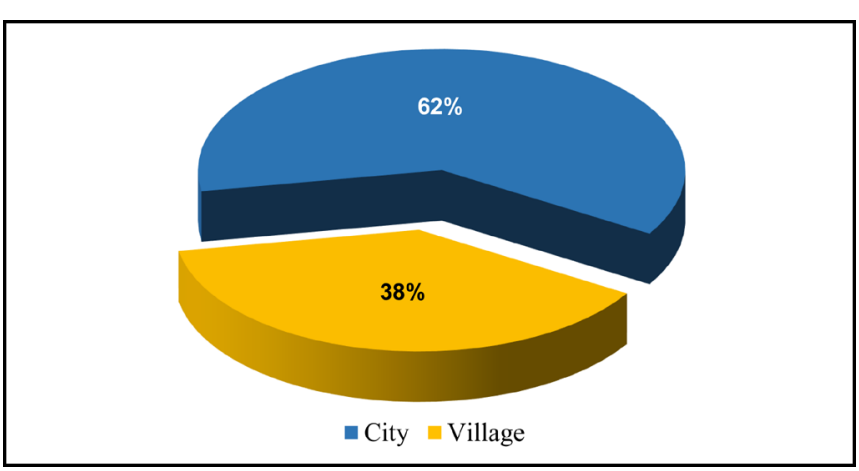

Depending on the total length of service, the participants are distributed as follows:

Most are the cases of the group with 21 to 30 years of a total length of service $-27,69 \%$.

The least cases are observed in the age group with over 40 years of a total length of service. Average total length of service is $22,02(n=65) \pm 2,94$ years. 
Fig. 6. Distribution of patients by the total length of service

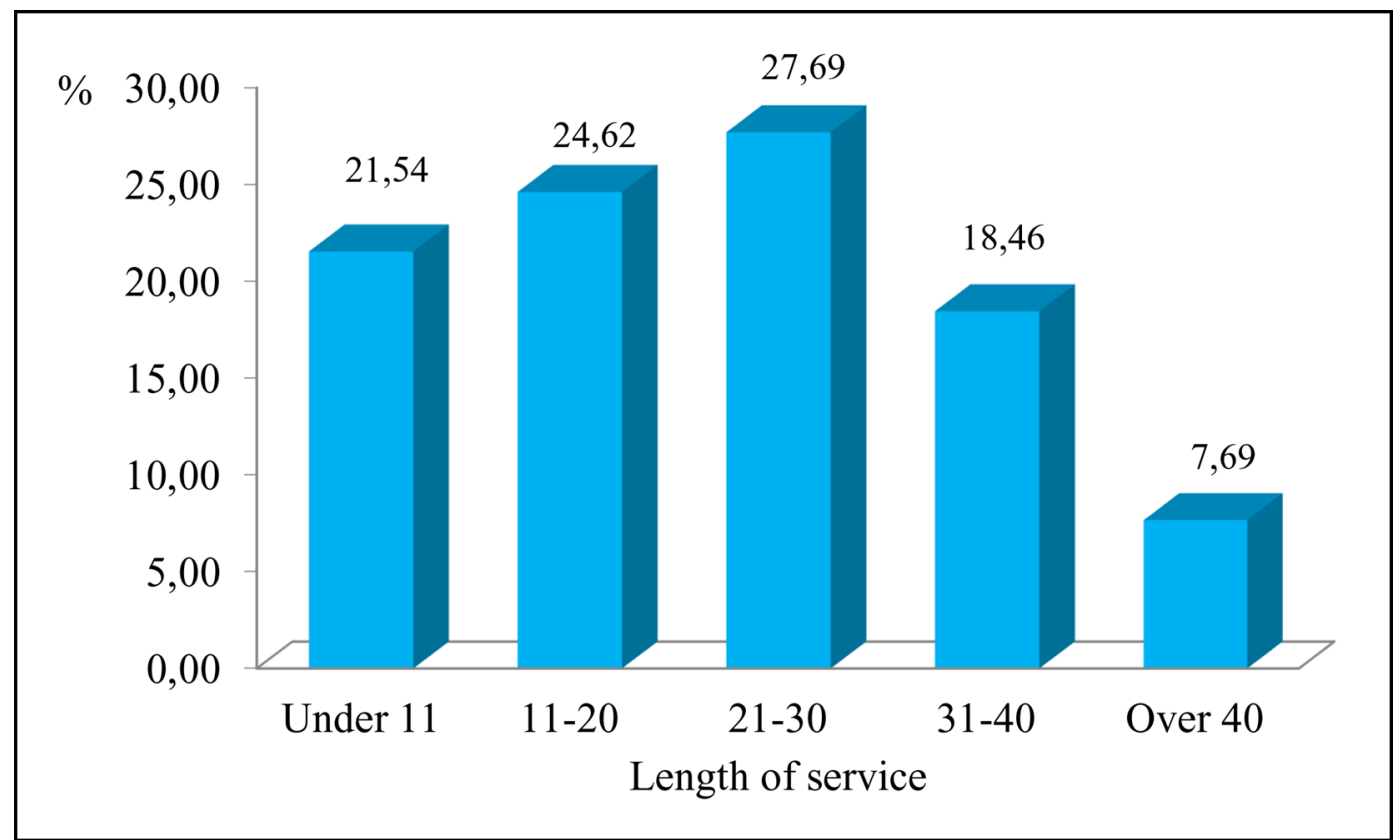

According to the contact with tools that generate vibrations, the persons are distributed as follows:

Yes $-60 \%$

No $-40 \%$

Distribution of residents by contact with vibration tools - Figure 7.

The distribution of the examined persons according to the formed clinical syndromes is the following: Pain 60 person; Radicular - 46 person; Vertebral - 35 person; Polyneuritis - 32 person.
Fig. 7. Distribution of residents by contact with vibration tools

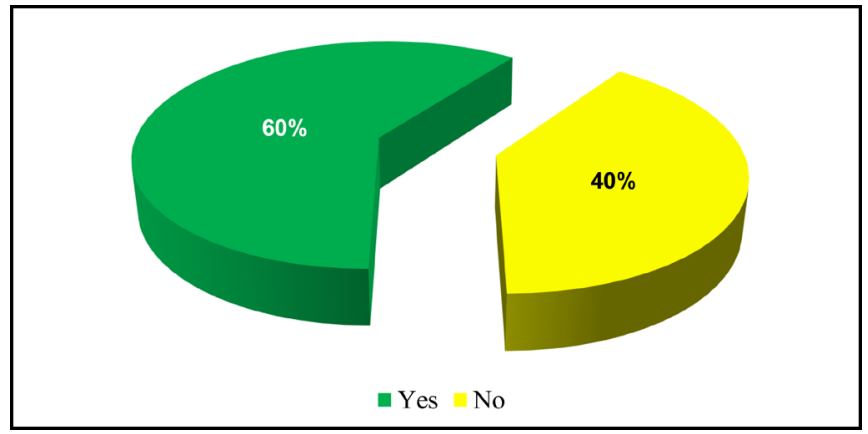

Fig. 8. Distribution by clinical syndromes

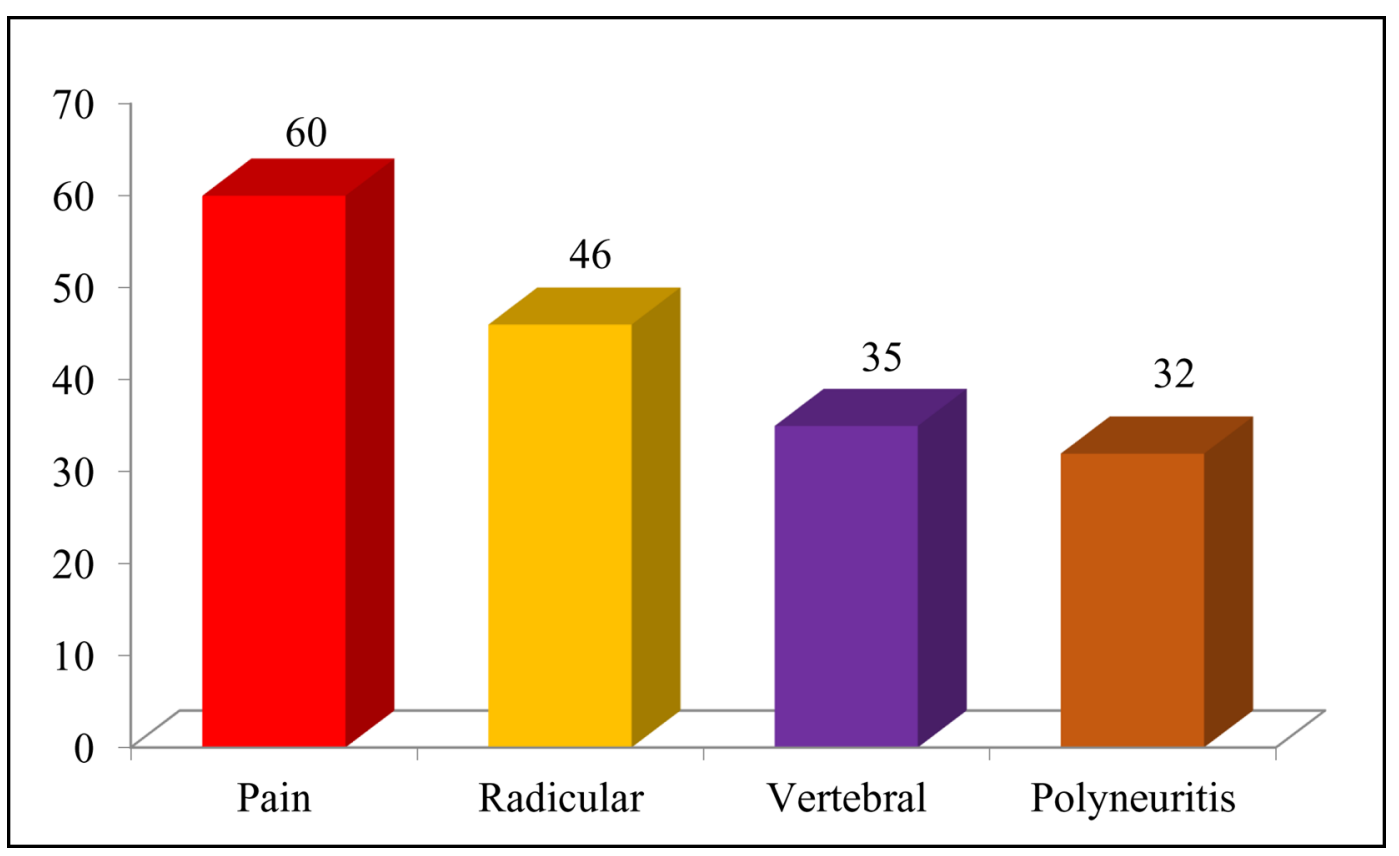


The distribution of participants, according to the intensity of pain, is shown in Figure 9.

Fig. 9. Distribution of persons by the intensity of the pain (VAS)

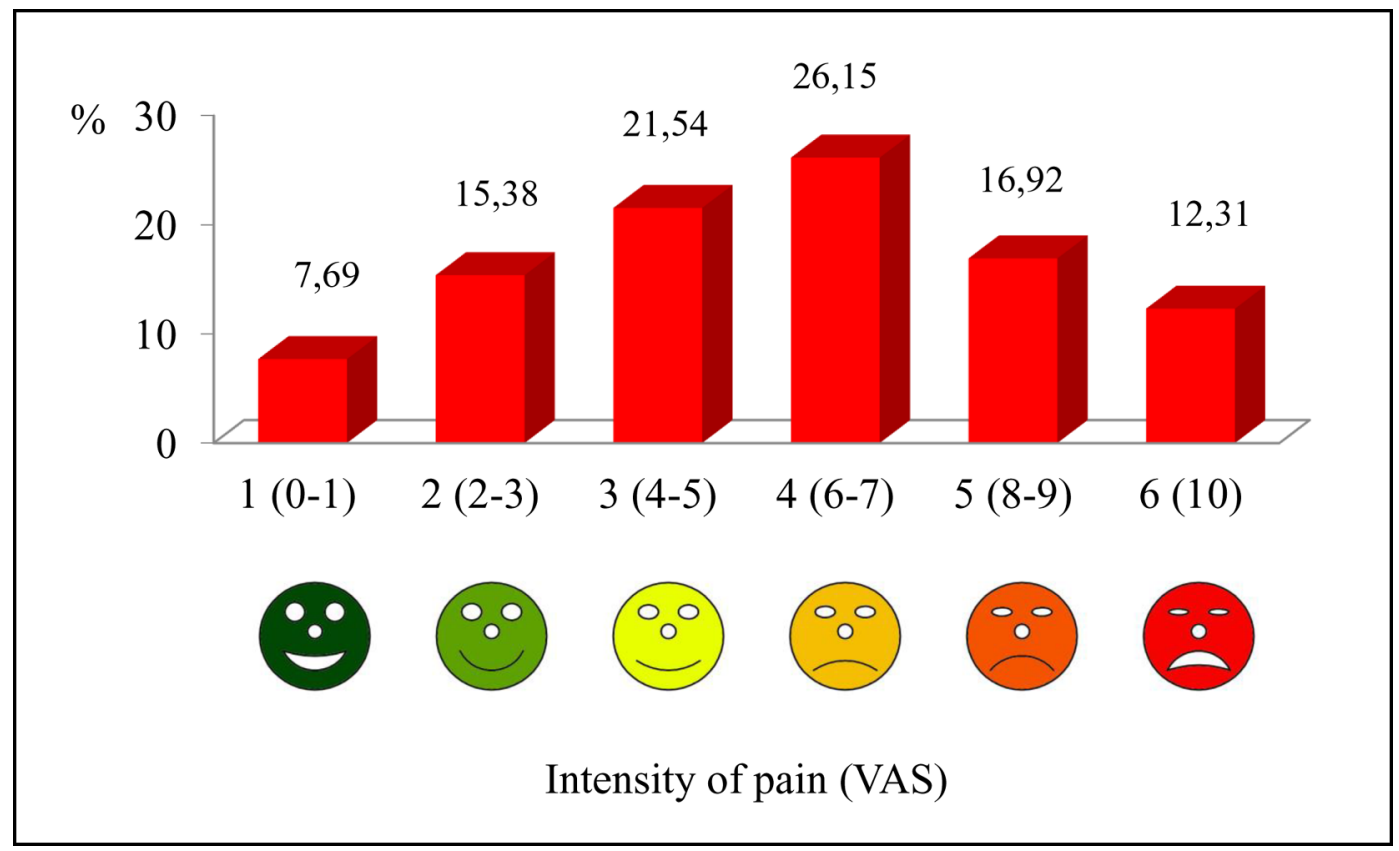

\section{DISCUSSION:}

A significant statistical dependence was found $(\mathrm{p}<0.05)$, showing a directly proportional relationship between the age of the persons and the degree of pain reported on the visual-analog scale (VAS). As the age of the person increases, the degree of pain increases. [8, 9, 10]

A correlation was found between the exposure and the degree of pain $(\mathrm{p}<0.05)$, showing a directly proportional relationship. The degree of pain increases with the increasing length of service of the subjects.

There is a correlation between residence and the presence of vertebral syndrome $(\mathrm{p}<0.05)$.

The vertebral syndrome is more common in study participants living in rural areas.

No significant correlation was found between the other studied indicators in the study participants [11].

\section{CONCLUSION:}

Damage to the peripheral nervous system is an actual health problem for people working in mechanical engineering in Northern Bulgaria.

The aging of the workforce is associated with involvement of the peripheral nervous system, characterized by pain syndrome.

An additional harmful factor for the occurrence of diseases of the peripheral nervous system in workers in mechanical engineering is the household load associated with the place of residence in the village.

RECOMMENDATIONS FOR PREVENTION MEASURES:

Physiological means - sleep, rational nutrition, active rest, hardening, training. Intensive work is recommended to take easily digestible oligosaccharides, which improve physical and mental performance and B vitamins and vitamin $\mathrm{C}$.

Medical prophylaxis - includes primary and periodic medical examinations. During the initial medical examinations, a physical and psychophysiological assessment of the candidate for work in mechanical engineering should be performed, taking into account the risk factors of production. Periodic medical examinations should record the exact condition of the worker, establishing the early manifestations of occupational injuries of the PNS and taking measures to prevent complications or chronicity of the disease.

\section{Ergonomic and organizational measures:}

- Rational organization of the labor process - by observing the established working hours; introduction and observance of a physiological regime of work and rest; conducting passive and/or semi-passive breaks while working in suitable premises.

- Control of the condition of the working premises: provision of sufficient area and volume; condition of walls, floors, ceilings.

- Control of the location of the equipment in accordance with the technological sequence; delineation of sufficient work areas and traffic area.

- Control of the parameters of the working environment: illumination, control of the zones of glare and glare; production microclimate, incl. ensuring a suitable temperature in the working premises; prevention of air currents.

Providing sanitary and living conditions: bathrooms, toilets, rest room. workplace.

Ergonomic control in the organization of the

For standing positions:

- Providing an opportunity to change the working 
position from upright to sitting by introducing a high, adjustable, fixed, swivel chair with a step.

- For workplaces where the work technology does not allow changing the working position to a sitting one, it is recommended to provide a chair for short-term rest.

- The work surfaces must be height-adjustable and positioned so as to allow the body to lean forward up to $15^{\circ}$ (for frequent bending) and/or up-to $30^{\circ}$ (for infrequent bending).

- Do not allow frequent stretching of the arms forward above the horizontal line at shoulder level.

- Do not allow the head to move left and right more than $30^{\circ}$ from the line of sight and more than $15^{\circ}$ in the up / down directions.

\section{REFERENCES:}

1. Tsvetkov D. [Occupational Saunders Co. July 1, 1994. pp.498Medicine. ] Sofia. 2008: 136-60. [in 502. [Internet]

Bulgarian]

2. Gatev S, Bankov S, Busarov S. [Manual of physical therapy.] Volume 2. Sofiia: Meditsina i fizkultura. 1992: pp.67-75. [in Bulgarian]

3. Gandev V. [Occupational Hygiene.] Sofiia: Meditsina i fizkultura. 1990: pp.128-139. [in Bulgarian]

4. Kirkov V. [Vibration disease.] In: Aleksieva Tsv, Kiryakov K, et al. [Occupational pathology.] Sofiia: Meditsina i fizkultura. 1982: pp.144155. [in Bulgarian]

5. Rosenstock L, Cullen MR. Textbook of Clinical Occupational and Environmental Medicine. WB
6. [Diseases of the hand.] Editors: Bosnev V, Matev I. Sofiia : Meditsina i fizkultura. 1989: pp.59-106. [in Bulgarian]

7. Charakchiev D. (editor) [Laboratory diagnostics of occupational diseases and ecopathology.] Bulgarian Publishing House Ltd., Sofia. 2006. pp.221-25. [in Bulgarian]

8. Khan NZ, Shihab SK, Attri R, Siddiquee AN, Khan ZA. Prioritization of lower back pain risk factors among industrial workers using the best-worst method. Int J Occup Saf Ergon. 2021 Jun;27(2):544-51 [PubMed]
9. Camino López MA, González Alcántara OJ, Fontaneda I, Mañanes M. The Risk Factor of Age in Construction Accidents: Important at Present and Fundamental in the Future. Biomed Res Int. 2018;2018:2451313. [PubMed]

10. López Arquillos A, Rubio Romero JC, Gibb A. Analysis of construction accidents in Spain, 20032008. J Safety Res. 2012 Dec;43(56):381-8. [PubMed]

11. Matveeva OV, Gurevich EB, Rodin SI, Fonova NG, Kungurova AA. [Some aspects of occupational spinal diseases.] [in Russian] Med Tr Prom Ekol. 2003;(9):8-10. [PubMed]

Please cite this article as: Stoilova IY, Madjarova RP, Birdanova VA. Occupational-related injuries of the peripheral nervous system in mechanical engineering workers in Northern Bulgaria. J of IMAB. 2021 Oct-Dec;27(4):4098-4102. DOI: https://doi.org/10.5272/jimab.2021274.4098

Received: 31/05/2021; Published online: 18/11/2021

\section{Address for correspondence:}

Irena Stoilova

Department of Hygiene Medical Ecology, Occupational Diseases and Disaster Medicine, Faculty of Public Health, Medical University of Pleven, Bulgaria.

1, Sv. Kliment Ohridski Str., Pleven, Bulgaria.

E-mail: irena.stoilova444@abv.bg 